\title{
Deforestation or Reforestation, A Time Series Remote Sensing Perspective of Wilpattu National Park, Sri Lanka
}

\author{
K.U.J.Sandamali ${ }^{1}$, D.R.Welikanna ${ }^{2}$ \\ ${ }^{1}$ Dpt. Remote Sensing and GIS, Faculty of Geomatics, Sabaragamuwa University of Sri Lanka, PO Box 02, Belihuloya, Ratnapura, Sri \\ Lanka \\ ${ }^{2}$ Dpt. Surveying and Geodesy, Faculty of Geomatics, Sabaragamuwa University of Sri Lanka, PO Box 02, Belihuloya, Ratnapura, Sri \\ Lanka
}

How to cite this paper: Sandamali, K.U.J. Welikanna, D.R. (2018) Deforestation or Reforestation, A Time Series Remote Sensing Perspective of Wilpattu National Park, Sri Lanka. Journal of Applied Mathematics and Computation, 2(10), 473-482. DOI: $10.26855 /$ jamc .2018 .10 .003

*Corresponding author: K.U.J.Sandamali, Dpt. Remote Sensing and GIS, Faculty of Geomatics, Sabaragamuwa University of Sri Lanka, PO Box 02, Belihuloya, Ratnapura Sri Lanka

Email: janakisandamali@gmail.com

\begin{abstract}
National parks by far could be considered as the heart of a countries bio network. This study attempts to identify and analyze the forest cover and its changes in the Wilpattu national park of Sri Lanka, which has grown into a level of a national crisis. The rapid utilization of remote sensing satellites and techniques has provided a reliable and near real time possibilities to characterize terrestrial ecosystem properties. In this study a series of Landsat imagery ranging from the year 1975 to 2015 have been used for the analysis. Initially, Support vector machine (SVM) based land cover classification was performed for all the images and the changes in the forest class was determined. Secondly Vegetation indices Normalize Difference Vegetation Index (NDVI), Normalize Difference Water Index (NDWI) Green Normalize Difference Vegetation Index (GNDVI) were used to separately extract the Vegetation, surface water and canopy conditions respectively. Deforestation rate was calculated based on definitions from FAO (Food and Agriculture Organization). The study found out that there is a reforestation inside the national park (annual reforestation rate of $0.17 \%$ ), while deforestation outside close to the boundaries of it (annual deforestation rate of $-0.29 \%$ ).
\end{abstract}

Keywords

DEFORESTATION, GNDVI, NDVI, NDWI, SVM, MARKOV CHAINS

\section{Introduction}

"The forest is peculiar organism of unlimited kindness and benevolence that makes no demands for its sustenance and extends generously that produce of life activity; it affords protection to all beings, offering shade even to the axe man who destroys it."

\section{Gautama Buddh}

Forest is not just a combination of some trees. It is a complex ecosystem consisting mainly of trees that buffer the earth and support a myriad of life forms. The importance of forest cannot be underestimated. We depend on forests for our survival, from the air we breathe to the wood we use. Besides providing habitats for animals and livelihoods for humans, 
forests also offer watershed protection, prevent soil erosion and mitigate climate changes. Yet, despite our dependence on forests, we are still allowing them to disappear.

\section{Study Area}

Wilpattu is one of the oldest National Parks in Sri Lanka. The park derives its name from the unique presence of many natural lakes or "villus" with fresh or brackish water in the area. Wilpattu Park itself is located in the lowlands. All of the land contained within the park is below 152 meters elevation and the majority of park land is less than 91 meters above sea level. The park and sanctuary are located in the northwest corner of Sri Lanka. The west boundary of the sanctuary area includes Portugal Bay. The north boundary of the park is set by the Moderagam Aru and the southern boundary by the Kala Oya.
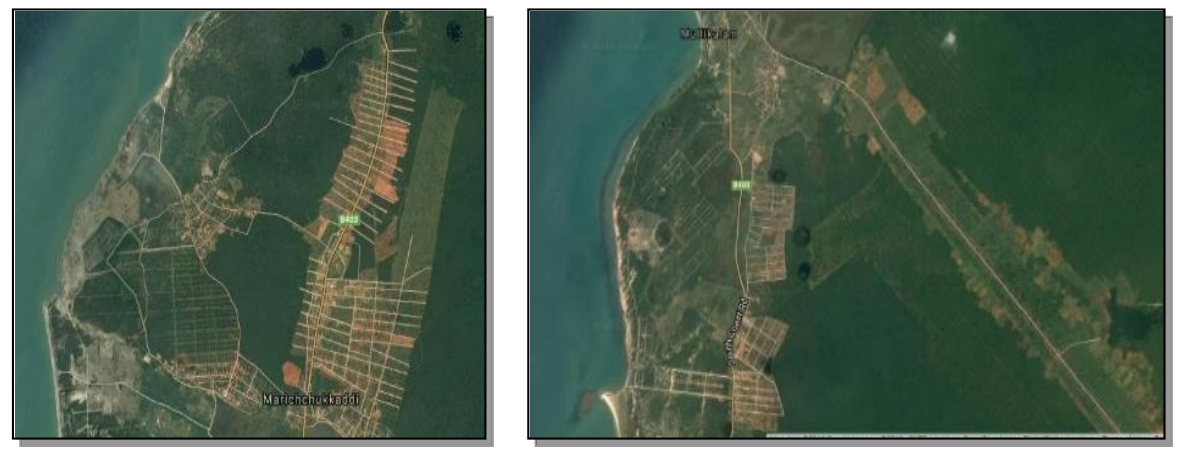

Figure 2.1. Google Earth images of deforested area outside Wil pattu National Park boundary (Marichchi katti, Kallaru, Wilaththeekul am and Karaduppuli Forest Areas).

Destruction of forest covers near Wilpattu National Park which has been going on since 2009. Wilpattu National park is a forest fragment which is surrounded by the network of forests such as Marichchikatti, Kallaru, Wilaththeekulam and Karaduppuli. There have not been any settlements in these areas at all, in the past. These forests are pretty much linked to Wilpattu National Park although these areas do not fall under the park rendering to administrative policies.

When considering wilpattu national park, we cannot consider this importance forest area as isolated structure. Simply we cannot assign margin for forest. For the Convenience of study, the study area was divide into two regions, area inside Wilpattu National Park boundary and Area outside Wilpattu National Park boundary.

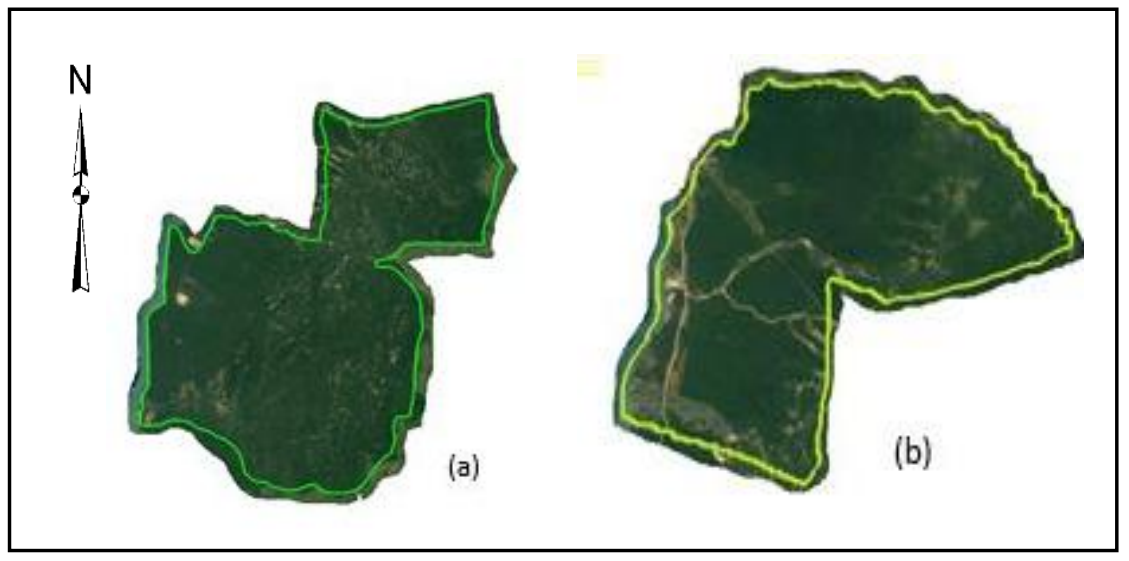

Figure 2.2. Google earth image of the Study area in the North coast of Sri Lanka, for (a) Forest area inside of Wilpattu National Park boundary and (b) Forest area outsi de of wilpattu national Park boundary (Marichchikatti, Kallaru, Wilaththeekul am and Karaduppuli Forest Area). 


\section{Data}

Time series of Landsat images were obtained from 1977 to 2015 from different platforms of evolution (Landsat 2, 5 and 8). The awareness of band combination is significant in study. Less cloud budget and haze were consider because, cloud content misclassify the classification result and misinterpret the result of NDVI. The following table describes the Landsat images used in this experiment.

Table 3.1. Landsat images on study (a) and (b)

\begin{tabular}{|l|l|l|l|l|l|}
\hline \multicolumn{5}{|c|}{ Area inside of Wilpattu National Park boundary } & \multicolumn{2}{l|}{ Area outside of Wilpattu National Park boundary } \\
\hline Year & Satellite & Dates & Year & Satellite & Dates \\
\hline 1977 & Landsat_2 & 26.01 .1977 & 1977 & Landsat_2 & 26.01 .1977 \\
\hline 1992 & Landsat_5 & 01.02 .1992 & 1988 & Landsat_5 & 06.02 .1988 \\
& & 25.01 .1992 & & & \\
\hline 1997 & Landsat_5 & 14.02 .1997 & 1992 & Landsat_5 & 01.02 .1992 \\
& & & & & 25.01 .1992 \\
\hline 2015 & Landsat_8 & 20.03 .2015 & 2009 & Landsat_5 & 03.03 .2009 \\
\hline & & & 2015 & Landsat_8 & 20.03 .2015 \\
\hline
\end{tabular}

\section{Methodology}

Pre-processing steps (radiometric calibration, atmospheric correction and mosaicking) were performed in order to obtain error free image for further processing. Radiometric calibration and the atmospheric correction was conducted according to requirements of the algorithm of Fast Line of Atmospheric Analysis of Spectral Hypercubes (FLAASH) in Environment for Visualizing Images (ENVI, version 5.1) software to retrieve surface reflectance.

support vector machine classification plays a major role in study and vegetation indices (NDVI (Normalize Difference Vegetation Index), NDWI (Normalize Difference Water Index), and GNDVI (Green Normalize Difference Vegetation Index)) use to validate the results that obtained from SVM classification. Calculation of the deforestation and reforestation rate is based on SVM classifications and definitions from FAO.

The overall experimental process in explained in Figure 4.1

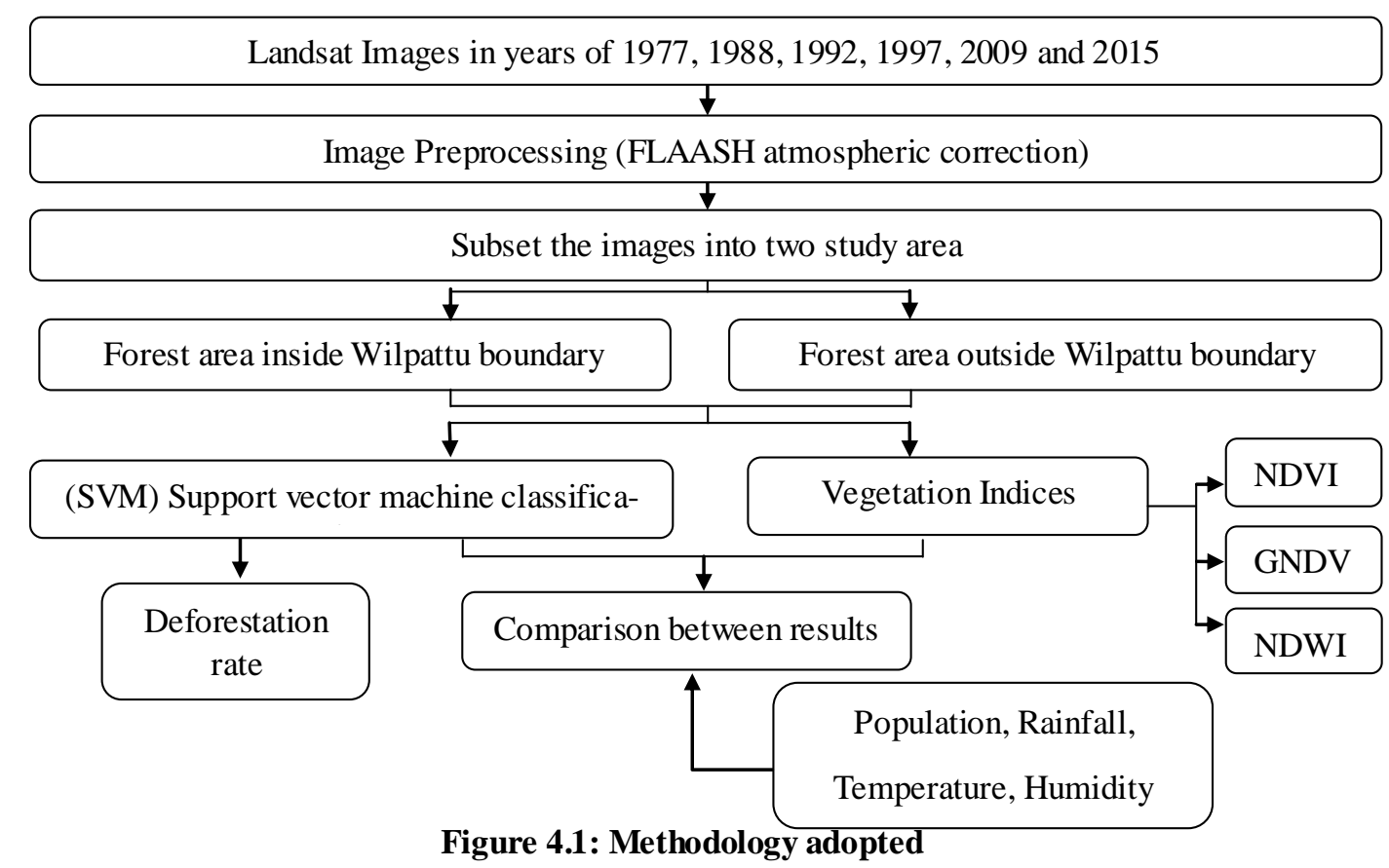




\section{Results And Discussion}

\subsection{Forest Area Inside of Wilpattu National Park Boundary}

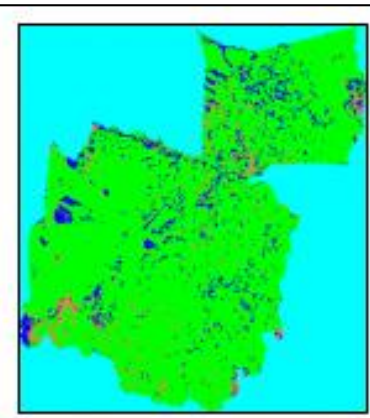

1977

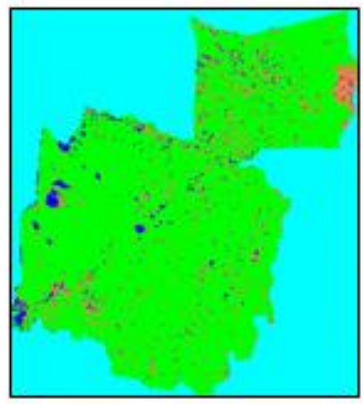

1992

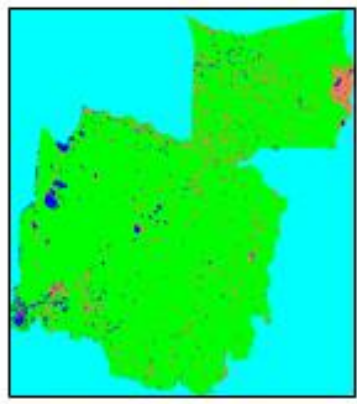

1997

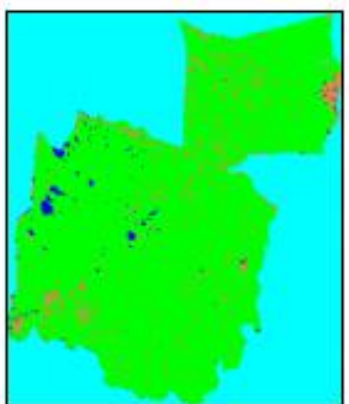

2015

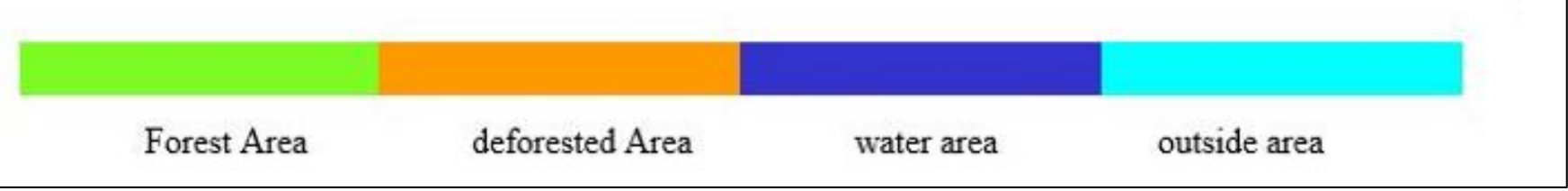

Figure 5.1.1 Support vector matching classification resulted images of forest area inside Wilpattu National Park boundary.
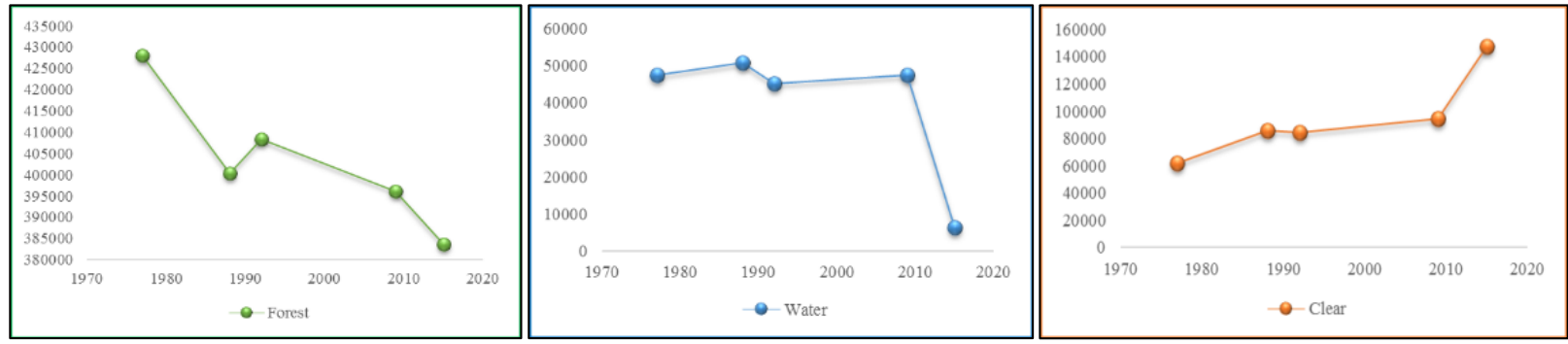

Figure 5.1.2 According to the SVM Classification (a) Graph of change of forest area (b) Graph of change of water area (c) Graph of change of unoccupied land are

According to the Figure 5.1.2, graph (a) it shows when time change from past to present, the forest area inside of wilpattu national park get increase and the bare lands get reduced, so with the gradual process the forest lands take over the bare lands. It shows there is a reforestation inside of wilpattu national park. Also according to the Figure 5.1.2, graph (b) indicates water areas getting reduced. This result as a result of some drought runs on inside of wilpattu national park, the forest area trend to acquire water bodies and grow algae towards the water bodies

Time series of NDVI and NDWI use to assess the accuracy of SVM classification result. Then temporal histogram based thresholding was done in order to discriminate the forest and water respectively. 


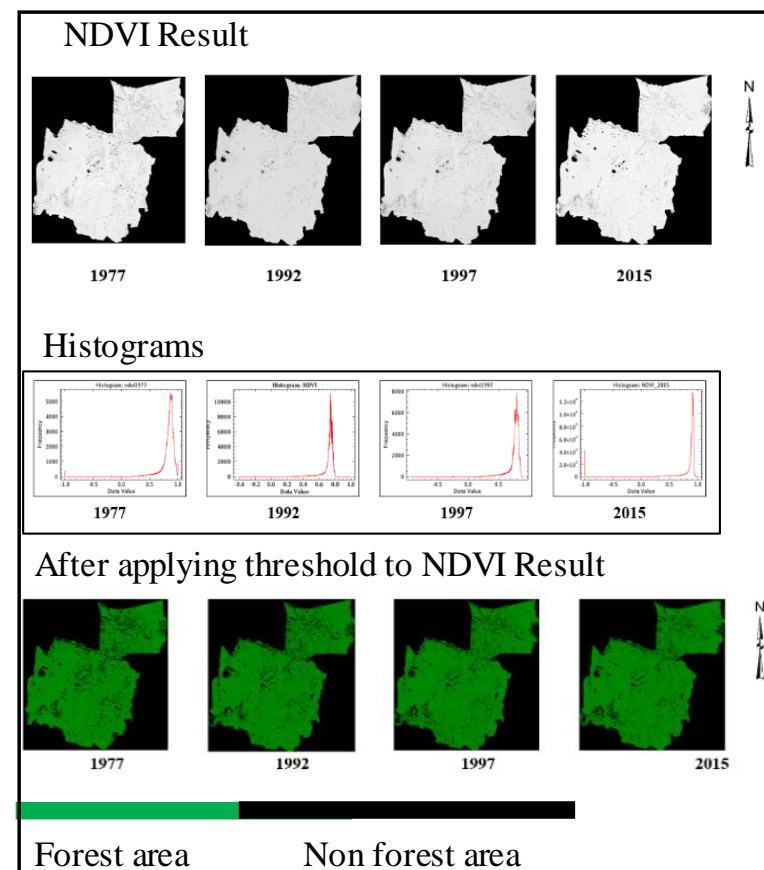

(a)

GNDVI Result

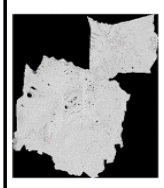

1977

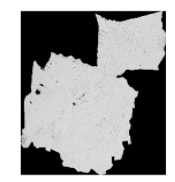

1992

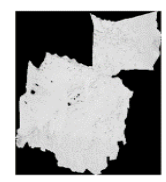

1997

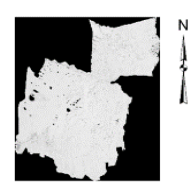

2015

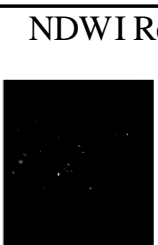

1977

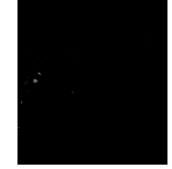

1992

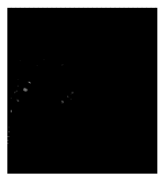

1997

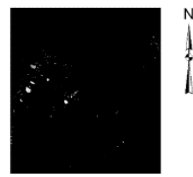

2015

Histograms

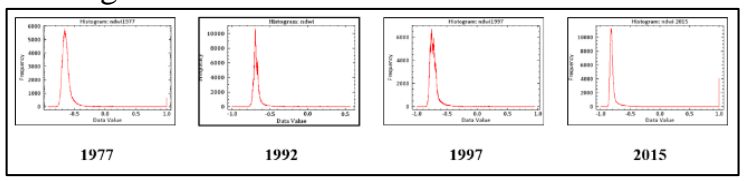

After applying threshold to NDWI Result

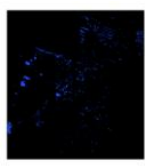

1977

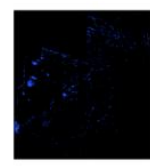

1992

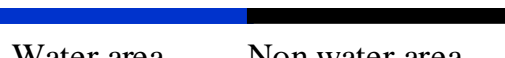

(b)

Histograms
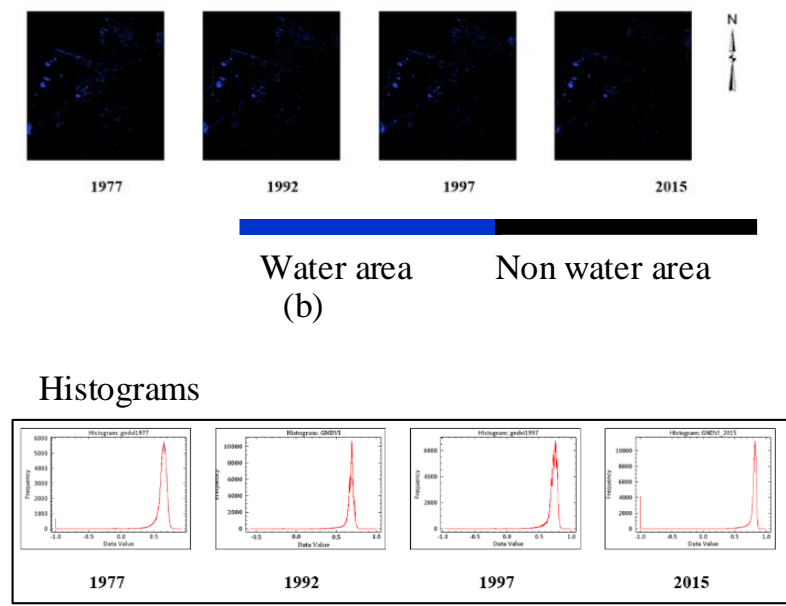

1997

Non water area

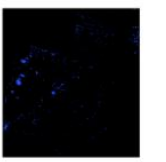

(1)

After applying threshold to GNDVI Result

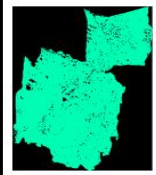

1977

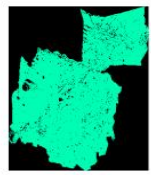

1992

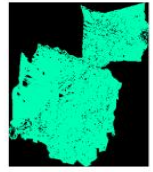

1997

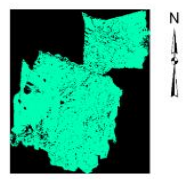

2015

Figure 5.1.3 According to the vegetation indices (a) NDVI results (b) NDWI results(c) GNDVI results

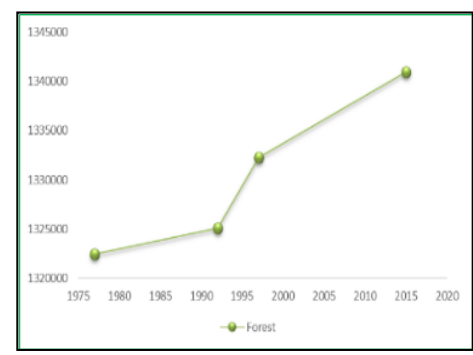

(a)

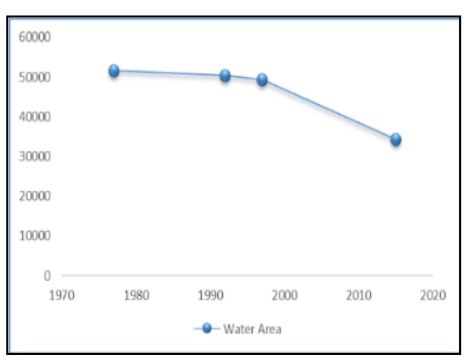

(b)

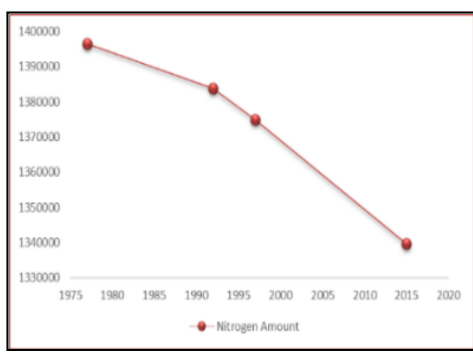

(c)

Figure 5.1.4 Graphs of change of (a) forest area according to NDVI threshold (b) water area according to NDWI threshold (c) Nitrogen emission according to GNDVI threshold in years of 1977, 1992, 1997 and 2015 
NDVI proportion to the amount of greenness. From past to present, result of NDVI intensification therefore there is a forest area encroachment inside the Wilpattu National Park (reforestation). NDWI proportion to the surface water area. It also epitomizes the water area inside Of Wilpattu National Park get diminution. Consequently there is a direct correlation among NDVI and NDWI resulted image and supervised classification result. Both emphasized the forest area getting amplified and Water area getting reduced. GNDVI proportion to the amount of nitrogen discharged. According to the figure it represent the nitrogen amount inside Wilpattu National Park has drastically reduced. Subsequently it illustration the fertility of soil slightly get reduction with the time.

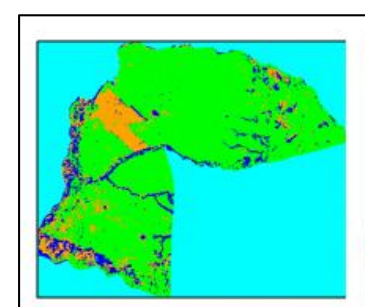

1977

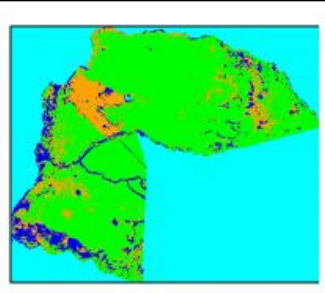

1988

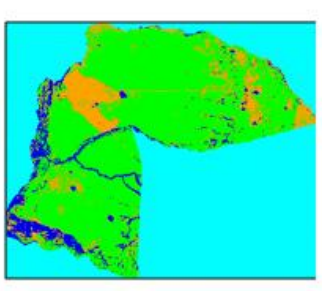

1992

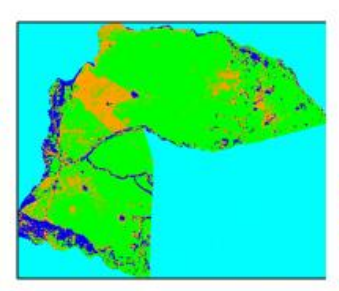

2009

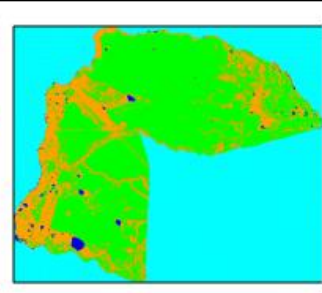

2015

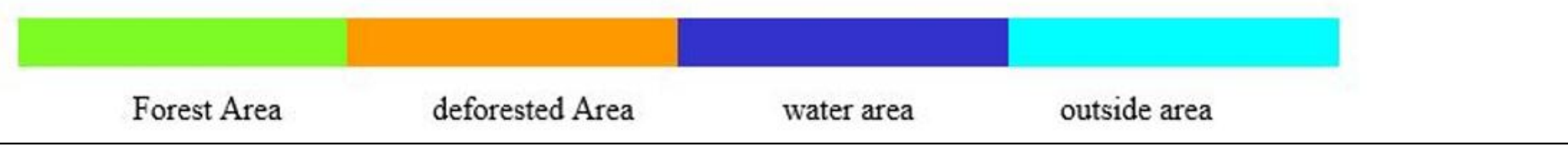

Figure 5.2.1 Support vector matching classification resulted images of forest area outside Wil pattu National Park boundary.

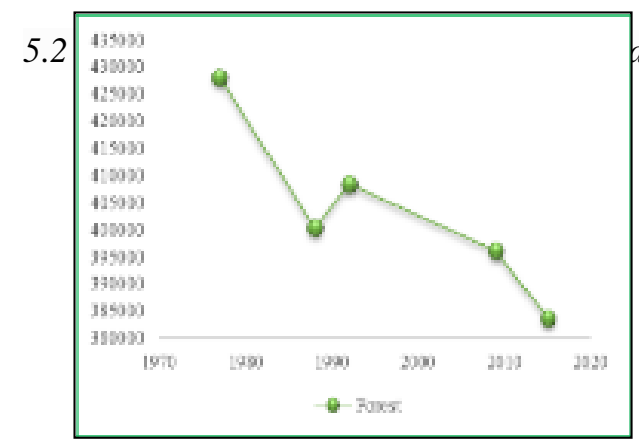

(a)

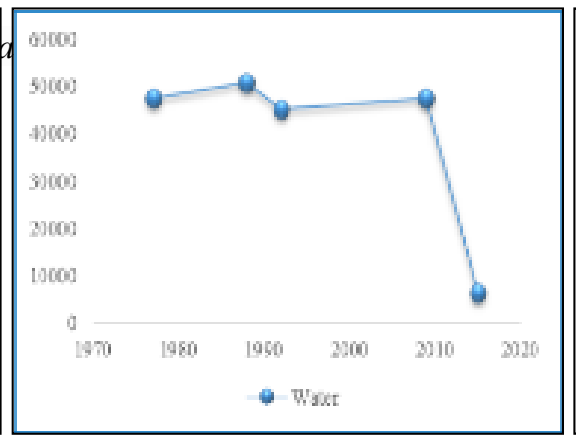

(b)

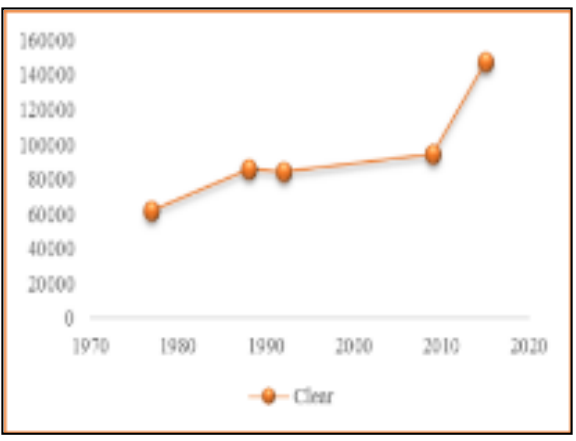

(c)

Figure 5.2.2 According to the SVM Classification (a) Graph of change of forest area (b) Graph of change of water area(c) Graph of change of unoccupied land area.

According to the Figure 5.2.2 graph (a) it illustration with the time, the forest area outside of Wilpattu National Park get decrease. It emphasize deforestation occurs in the outside area of Wilpattu National Park. The Figure 5.2.2 graph (b) illustrate the water area get reduction and the Figure 5.2.2 graph (c) illustrate the deforested area get increase. Mainly its cause's resettlement on these areas and also construction of road network.

Time series of NDVI and NDWI use to assess the accuracy of SVM classification result. Then temporal histogram based thresholding was done in order to discriminate the forest and water respectively 


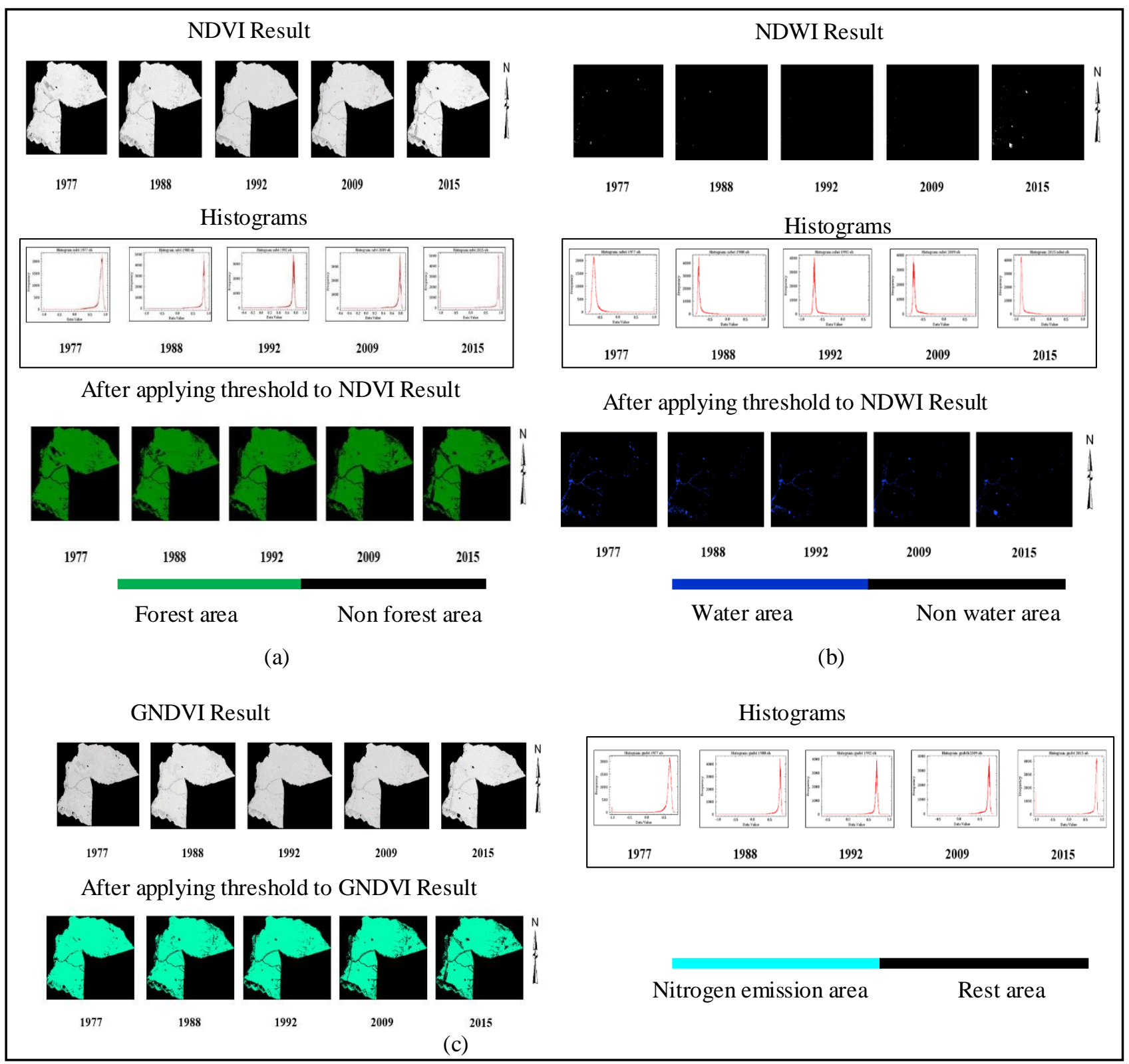

Figure 5.2.3 According to the vegetation indices (a) NDVI resul ts (b) NDWI results(c) GNDVI resul ts

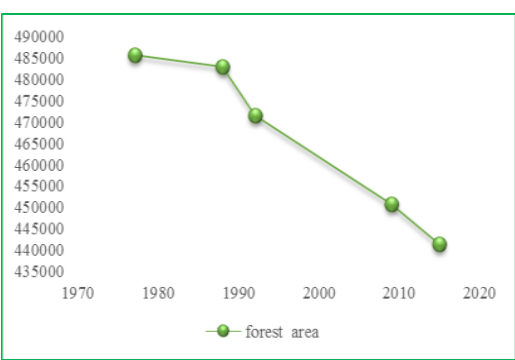

(a)

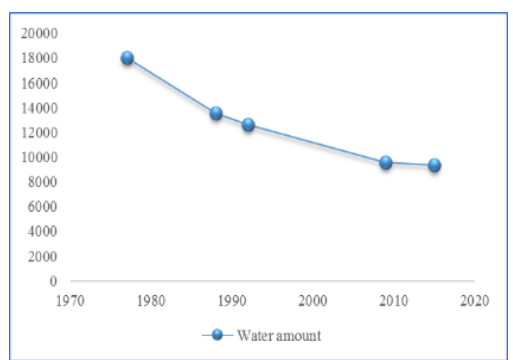

(b)

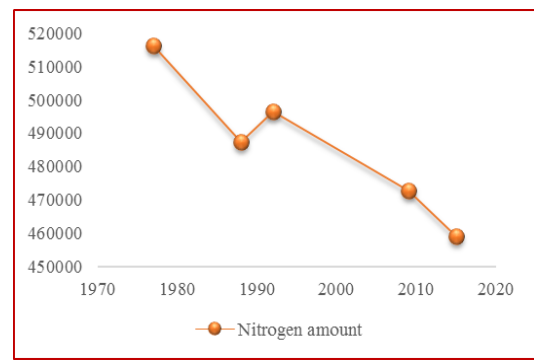

(c)

Figure 5.2.4 Graphs of change of (a) forest area according to NDVI threshold (b) water area according to NDWI threshold (c) Nitrogen emission according to GNDVI threshold in years of 1977, 1992, 1997 and 2015 
The NDVI result reduced with the time therefore it represent that the forest area outside of Wilpattu National Park getting substantially declined. Therefore it specifies deforestation and NDWI proportion to the surface water area. Thus the graphs represent the water area inside of Wilpattu National Park getting reduced. SVM results confirmed this observation. Consequently then can see direct relationship among NDVI and NDWI resulted image and supervised classification result. Both point out same result as previous. GNDVI proportion to the amount of nitrogen emitted. According to the Figure 5.2.4, graph (c) it represent the nitrogen amount get slightly decrease. Consequently the fertility of soil slightly get reduction also in outside of Wilpattu National Park with the time change.

\subsection{Change of Other Social and Natural Components around Study Area}

For an accurate research of deforestation requires analysis of its impacts. This impact may be direct or indirect. As indirect impact of deforestation cause to temperature increase, less rainfall, air pollution, diminish natural water bodies, causing droughts etc. In this study the study area deal with three districts of Sri Lanka. They are Anuradhapura, Puttalam and Mannar. In here mainly consider two components, social components and natural components. By means of social components only consider about population and for natural components consider temperature, humidity and rainfall.

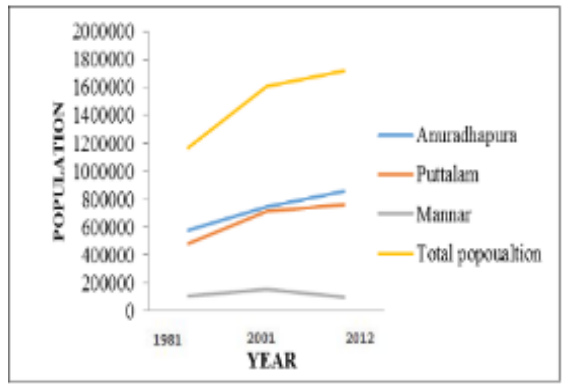

(a)

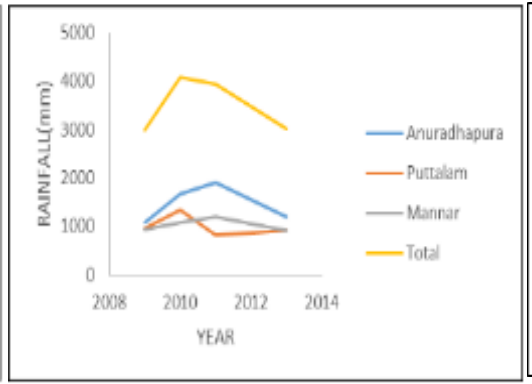

(b)

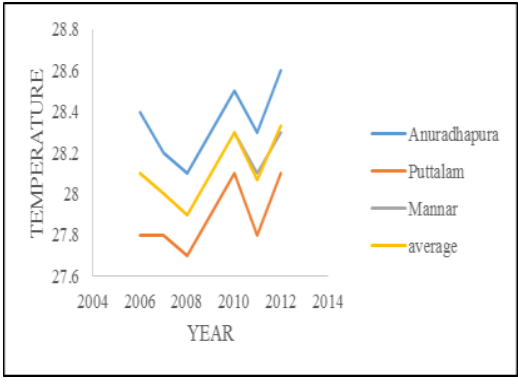

(c)
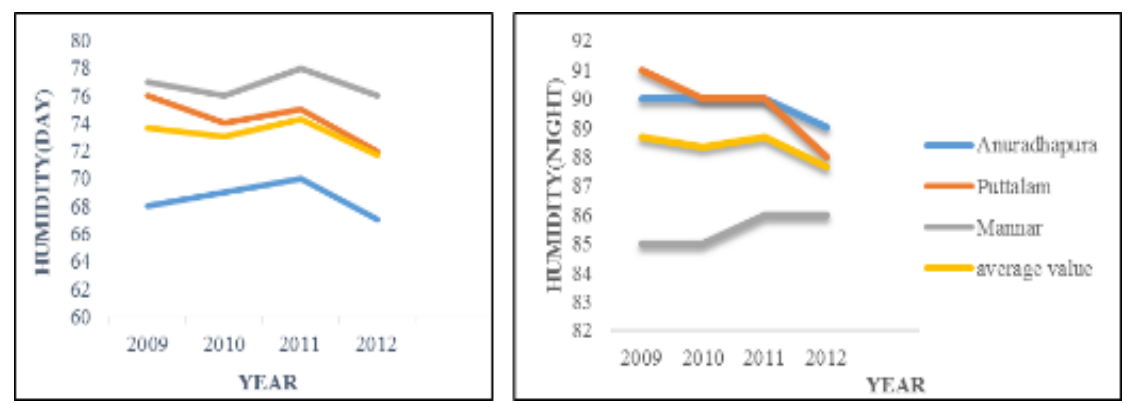

(d)

Figure 5.3.1 (a) Population (b) Rainfall (c) Temperature (d) Humidity day and night, in three districts belongs on study area.(Source: Department of Census and Statistics Sri Lanka.)

When in view of these graphs it shows there is a relationship between the results of the study and variation of components. When considering in these areas the population get increased because of resettlements, consequently it could be one major reason for the degradation in forest. For the reason that, increase of population is not favorable for forest areas. Hence in this research it demonstrations there is deforestation outside the forest area. Inside forest area is manage by Department of Wildlife Conservation so people restrict to enter these protected zones. But outside forest area is unprotected and vulnerable for human activities. It's very risky to the nature.so its causes to deforestation. When in view of natural components of the area the average values of rainfall get decrease, temperature gets increased and humidity get 
decrease. It's not good condition for nature. It is not possible to state that meteoroidal parameters showing hazardous fluctuations due to deforestation, but it are indeed one main fact. But can assume deforestation has some influence to those components.

\subsection{Calculation of Change Rates}

When allowing for area inside of wilpattu national park the forest area get increase with the time therefore it reveal reforestation with annual reforestation rate $0.29 \%$ and the reforestation area 104.87 hectares per year. The outside of Wilpattu National Park, with the time the forest area get decrease subsequently it indicate deforestation with annual deforestation rate $-0.17 \%$ and the deforestation area 203.72 hectares per year.

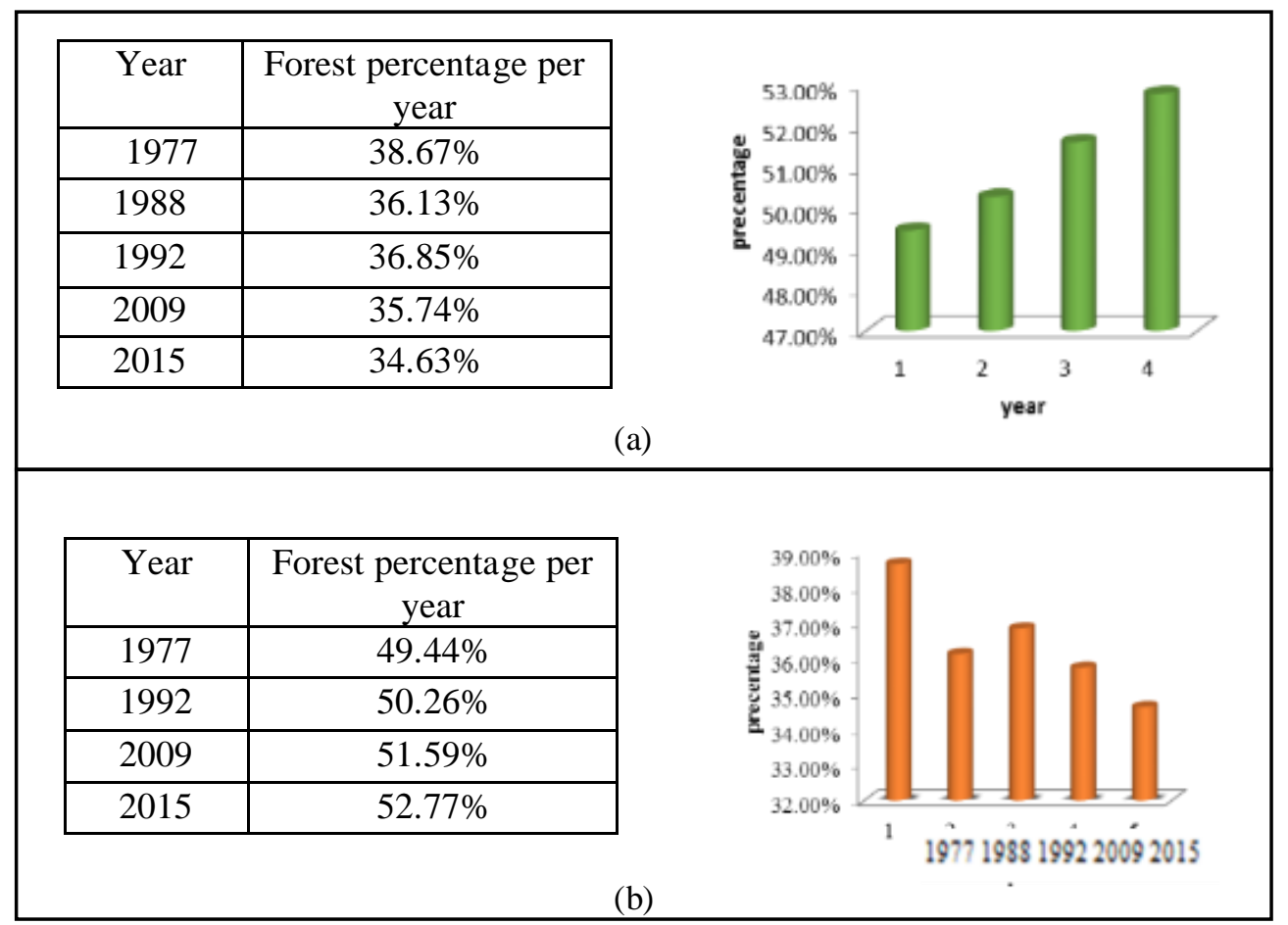

Figure 5.4.1 (a) Forest area get decreased in outside the wil pattu boundary (Deforestation) (b) Forest area get increased in inside the wilpattu boundary (Reforestation).

\section{Conclusion And Recommendation}

The major problem of working with optical images is clouds and ground cover may cast shadows on the target. The mapping of the submerged vegetation using optical remote sensing from airborne sensors is a bit more difficult.

All classification techniques have advantages and disadvantages, which are more or less important according to the data which are being analyzed, and thus have a relative relevance. SVMs can be a useful tool for insolvency analysis, in the case of non-regularity in the data, for example when the data are not regularly distributed or have an unknown distribution SVM provide virtuous result. When considering support vector machines it is Effective in high dimensional spaces and effective in cases where number of dimensions is greater than the number of samples, Uses a subset of training points in the decision function (support vectors), so it is also memory efficient. But if the number of features is much greater than the number of samples, the method is likely to give poor performances. 
SVM is efficient classification method with clear ground truth samples but it's not good to analyze various kind of vegetation types at once. When it's with further vegetation types the ROI separability index not provide virtuous outcome. With the effect better to practice deforested and forest area directly as ground samples with high accuracy. It's better to use ground truth collection for supervised classification. Ground sample collection also helps to identify current situation of study area. In this study some water bodies covered with algae so it's difficult to identify with Google Earth images. Better pattern recognition technique can be obtain even from the low resolution freely available satellite imagery because of the less data content but with the advance image processing techniques.

\section{Acknowledgement}

We would like to acknowledge every person who helped us in different ways during the research work. Especially our heartiest thank goes to our supervisor, the Head of the Department of Surveying and Geodesy Dr. Duminda R. Welikanna for giving us maximum support to complete this study successfully and supplying necessary arrangement, valuable guidance, advices with greater motivation and also appreciation to carry out the task successfully from beginning to end.

\section{References}

[1] Ayoola Akinola Akingbogun, Oloyede S.O.A Kosoko and D.K Aborisade,2012, Remote Sensing And GIS Application For Forest Reserve Degradation Prediction And Monitoring, First FIG Young Surveyors Conference Knowing to cre ate the Future, ROME, ITALY.

[2] Biodiversity Conservation in Sri Lanka - A Framework for Action - Publication of the Ministry of Environment and Natural Resources.

[3] Census of Population and Housing,2012, Department of Census \& Statistics Ministry of Policy Planning and Economic Affairs, Department of Census \& Statistics, 'Sankyana Mandiraya', , Battaramulla,SRI LANKA.

[4] C. J. Tucker and J. R. G. Townshend, (2000), Strategies for Monitoring Tropical Deforestation Using Satellite Data, Laboratory for Terrestrial Physics, NASA/Goddard Space Flight Center, and Greenbelt, MD 20771, USA

[5] David Skole and Compton Tucker, Tropical Deforestation and Habitat Fragmentation in the Amazon: Satellite Data from 1978 to 1988.

[6] IDRISI Guide to GIS and Image Processing Volume 1, Introduction to Remote Sensing and Image Processing.

[7] LANDSAT 8 Data Users Handbook, 2015 Department of the Interior U.S. Geological Survey.

[8] Mangala De Zoysa, (2001)A Review of Forest Policy Trends in Sri Lanka, Department of Agricultural Economics, Faculty of Agriculture, University of Ruhuna, SRI LANKA.

[9] Piyasena Abeygunawardena and Jeffrey R. Vincent'1993, Bare Knuckles: Fighting Deforestation in Sri Lanka, Harvard Institute for International Development.

[10] Rajlaxmi Chouhana, Neeraj Rao b, Vegetation Detection In Multispectral Remote Sensing Images: Protective Role-Analysis Of Vegetation In 2004 Indian Ocean Tsunami, PDPM Indian Institute of Information Technology, Design \& Manufacturing Jabalpur, INDIA 